\title{
BIM METHODOLOGY APPLIED TO ARCHITECTURAL HERITAGE PRESERVATION: CASE STUDY OF THE MEDINA AND DUNGEONS OF TETUÁN, MOROCCO
}

\author{
GIACOMO SORINO ${ }^{1}$, CARLO MANFREDI $^{2} \&$ ANTONIO JIMÉNEZ DELGADO $^{3}$ \\ ${ }^{1}$ Politecnico di Bari, Italy \\ ${ }^{2}$ Ministero per i Beni e le Attività Culturali, Italy \\ ${ }^{3}$ Universidad de Alicante, Spain
}

\begin{abstract}
The aim of the proposed contribution is to investigate how the application of BIM methodology in the field of the architectural heritage can avail both the study of an historical building and its subsequent preservation. Starting from the analysis carried out in the Medina and Dungeons of Tetuán (Morocco), we propose a H-BIM (Historic Building Information Modelling) methodology focused on the pathological parametric study of the buildings (as-damaged model) and therefore obtain a specific information database for each architectural element. The goal of the work is to establish a digital parametric methodology that is both inherent to the pathological and geometric study of a vivienda of the Medina as well as applicable to diverse cases within that realm, starting with a hybrid traditional (CAD) and innovative (photogrammetry) database combined. Furthermore, the hybrid workflow allows to rise above the limitations that the (geographical) distance often presents from case studies and it allows overcoming the common difficulties encountered in a traditional restoration-conservative study in finding information. The choice of this particular case study enables evaluating the updatability of an H-BIM model and therefore the possibility of containing different information dating back to different phases of survey and project that can be parameterized and compared, with the aim of ensuring both the historical traceability of the degradation of the asset and its architectural composition over time. Lastly, an H-BIM catalogue of the different viviendas which were analysed in the preliminary phase is proposed, starting from a typical house in the Medina of Tetuán, so as to initiate a realistic data collection of the Medina of Tetuán with the aim of undertaking a preventive restoration without having to resort to interventions of emergency and structural reinforcement as foreseen in the case of the Ben Marzouk house and the dungeons (mazmorras).
\end{abstract}

Keywords: cultural heritage, H-BIM, Tetuán, digitalization.

\section{INTRODUCTION}

Tetuán is a city of northern Morocco, capital of the part once submitted to the Spanish protectorate. The city lies in a pleasant position amidst gardens and orchards, on the southern slopes of the Sierra del Haus located on the left bank of the Río Martín at $10 \mathrm{~km}$. from the coast. It is believed that Tetuán was built on the site where the ancient Tamuda existed already at the beginning of the 14th century by a chief Merinide. In the 15th century, Tetuán was taken and destroyed by the Spaniards, but a century later Moors and Jews, expelled from Spain, repopulated it. A period of considerable prosperity for trade and for the industries that were practiced there began, and it continued even after that its port was blocked. In 1859 the Spaniards temporarily reoccupied Tetuán following the aggression suffered by the caravan of Prince Albert of Prussia coming from Ceuta; but for the peace treaty of the following year, which secured other advantages for Spain, the city was later released. Following the international agreements that regulated the division of the Moroccan protectorate, Spain proceeded to its regular occupation and made Tetuán the capital of the Protectorate and of the ancient Presidios. In 1933 Tetuán counted 48000 inhabitants, of which many Jews and Spaniards, for whom a special district adjacent to the ancient old city called Medina was built after 1913. 
Reading the traces of such a complex stratification, interpreting the signs that affect the buildings - from economic, political, military and religious reasons - constitutes an articulated research path, which we will try to describe here in this paper. Of course, not all points can be fully investigated. The understanding of the evolution of the built heritage in its characters is also not immediately recognizable. It is also necessary to formulate a broader reflection on the present consciousness and future potential. The aspects that have connected the episodes of Tetuán in a homogeneous fabric must be fully recognized, as well as the dimension of the project, on the architectural and urban scale, achieves a coherent awareness.

\section{METHOD}

It is proposed to investigate the material consistency of the artefacts, following all possible clues that may lead to different aspects related to production (construction) in terms of materials and techniques to obtain credible results. In the context of the longue durée events [1]. In particular, the tools offered to the investigator, at least potentially, in this first phase of investigation, are constituted by paths that must necessarily be investigated in a differentiated manner depending on the specific possibilities of each case. In summary, this research is about framing the useful sources for a documental investigation, reading the constructive stratification of the objects and formulating proposals for instrumental diagnosis in the most controversial cases.

All the described routes still adhere directly, to some extent, to the architectural research method as it has been structured in scientific headquarters in recent decades: in fact, all approaches deal with the history of architecture, the history of construction, the archaeology of architecture [2] and historical research stricto sensu.

\subsection{Scientific tools}

Starting from this kind of background, on which to begin a direct knowledge, the chapter of archaeological research opens by applying well-established methods of understanding of the built heritage to the specific cases. These methods, developed in the last decades in Europe, have quickly become the common ground of the discipline also in Spain, where the road has been paved since the thirties with sensitivity towards the on-going debate in other countries in recent years [2], [3]. This research is about identifying the constructive character of the existing buildings, especially isolating those techniques and materials that know a peculiar development in this area. The techniques of archaeological research are based on the connection between the elements of the construction in relation with the later stages in which the life of the building has developed. It is a method of analysis of stratification born in the world of archaeology and, at first, was predominantly applied to archaeological stratification [3]: in the case of a true analysis and not just a reading, the definition of "constructive stratigraphic analysis" seems more appropriate. At the base of this approach is the understanding that the building can always be interpreted as a palimpsest, which bears the mark of constructive vicissitudes (and sometimes even historically relevant in the broadest sense) that have affected it throughout his life. A diachronic understanding of the artifact leads to the awareness of how certain realizations, constructive techniques and materials are directly related to a phase of the work or maintenance and can in fact reveal the relationship with the context. Consequently, the building becomes a potentially unlimited source of knowledge, which can be interpreted following different paths and discordant methods or, better, divergent lines of reading.

The H-BIM become part of this approach, as depicted in the following paragraphs. The ever increasing debate in the scientific press regarding BIM technologies is very vast at 
the moment, and it will not be discussed here. The acquisitions of the applications are carried out with rapidity and are always overcome by new developments. For a review of the literature, see the review cited in the bibliography [4].

\subsection{The project for the Medina}

The intervention project on the historical heritage with H-BIM takes as its scenario the Medina of Tetuán declared World Heritage Site in 1997 by UNESCO. Together with the Spanish Ensanche, the Medina of Tetuán draws one of the most interesting and best-preserved urban environments in Morocco.

In the late fifteenth and early sixteenth centuries, the Moors expelled from the Iberian Peninsula built the Medina intending to reproduce, on the other side of the Strait, Al Andalus. The Medina of Tetuán presents a living heritage which can be perceived even by walking through its labyrinthine streets where centuries of history permeate the houses and the people who inhabit them, a history shared between Spain and Morocco.

A rich tangible and intangible heritage models a living city where we analyse a double reality, the great beauty of its constructions and the evidence of its fragility and need for conservation. H-BIM is a tool of great potential in the context of a historical centre of these characteristics. The research project is developed over a decade from 2009 through 2019 and carried out by the research group Aedificatio in collaboration with the Tetuán Asmir Association and Tetuán institutions. The main objective is the conservation and enhancement of the historical-architectural heritage of the city using H-BIM methodology. The Medina and its dungeons constitute the strategic axis.

The Medina of Tetuán has an inherent value to its buildings of great architectural wealth. All this is inseparably linked to the traditions and customs of its inhabitants who walk its streets daily. The analysis of the most significant constructive exponents implies the dynamization of necessary conservation processes in all areas of the city. Specifically, this case serves as a reference for learning a current project that contemplates the sustainable development goals established by the United Nations. The project establishes the following lines of work:

- Intervention and conservation in heritage.

- Citizen participation.

- BIM methodology applied to heritage.

For an adequate intervention and conservation of heritage, the Medina space is conceived of as a container of materialized culture in its constructions, in which we can recognize historical-artistic values.

Citizen participation and the inclusion of the data obtained in the project structures a new form of document with sociological elements. Participatory techniques by citizens are central and significative to the process. The methodological strategy that is proposed is known as bottom-up because it allows the community to be approached from diverse and pluralistic individuals. It is important to know how space is configured and the experiences that take place in the city to identify the factors that are problematic in their urban conformation and that affect life. The knowledge of sociological elements brings us closer to responses of an identity type necessary for the development of a constructive intervention in historical exponents.

Participatory workshops offer citizens a space for debate about future expectations in the urban context. These workshops involve groups and associations with diverse interests that offer the necessary information in the project. 
To the information of materials and constructive solutions, we incorporate sociological information of a historical and contemporary nature that helps us establish a rigorous database. The analysis of this data in Tetuán projects and in other cities of Islamic origin such as Granada will inform future knowledge of colours, materials, techniques, craftsmen, etc. for the constructive intervention in the historical heritage with important data on identity in the historical space of Islamic cities.

\section{H-BIM}

The idea, therefore, that we want to implement, and that we believe is indispensable today, is that BIM does not only serve large-scale projects, or offices that have a massive organization of teams and architects. Contrary to what is thought, carrying out a project with BIM methodology does not require costly technological means, on the contrary, a BIM research can be executed with every-day technology. The purpose of the project "Metodologia BIM e rilievo a servizio di architetture tradizionali" carried out between the Politecnico di Bari (Italy) and the University of Alicante has demonstrated that, with minimal technological means such as a camera and a laptop, one can perform a modelling with photogrammetric methodology to analyse and develop an intervention project on a historic building, and beyond, on an entire neighbourhood or environment.

What is H-BIM? How can it really be effective in the field of restoration, and more precisely in an environment like that of the Medina of Tetuán? The goal of H-BIM is certainly to be able to simplify the processes of preservation, study and management of the historic building, but at the same time to allow a correct integration between different factors that, otherwise, would remain isolated and probably not even considered.

Based on new methodologies such as photogrammetry, information and traditional knowledge can therefore be integrated with a technological database, which allows a $360^{\circ}$ picture of the building complex, both from the point of view of the characteristics and from the point of view of the life cycle. It has become indispensable to treat an architecture considering its entire life cycle, from the conception to the subsequent demolition or reconversion, all the more so if we talk about the restoration of buildings of significant historical value. So being able to create a virtual prototype that contains all types of information available in the field and beyond allows us to have a global view of pathologies and their possible solutions as well as a global vision of the past of the building itself, characterizing the degradation processes that have reached us. The implementation of the HBIM must therefore concern not only the architecture itself, but also all that characterizes its essence, up to the notions handed down orally by the neighbourhood resident or by the native mason of the area.

Although the goal is to achieve a global understanding of the architectural good and to therefore describe it in all its tangible aspects, the main resource that characterizes and distinguishes the H-BIM method is the creation of an image-based photogrammetric model, i.e. photogrammetric, or range-based, that is, through laser scanner. We therefore try to change the paradigm of the survey phase, where it is possible, through new technologies and the parameterization of information, to carry out a study and a survey that is more complex but at the same time more complete.

Creating an H-BIM project means starting from a "remotely sensed" database, applying methods and technologies pertaining to the field of photography and photogrammetry. The phase of relief is probably the most important phase for a restoration project, especially in the case in which one finds oneself in front of buildings of high historical value and characterized by a strong structural deficiency and presence of pathologies. In the case of the traditional survey, human and temporal resources assume an important weight, probably 
making up for a lack of technical and economic resources. On the other side, what most characterizes a photogrammetric survey is the reduction of time and human capital in favour of technical development and growing technology.

The reduction of time and costs takes place not only during the architectural relief phase, but also and above all it refers to the reduction in subsequent phases of realization of the photogrammetric model and the parametric model. One of the characteristics of the photogrammetric model is in fact the possibility of being able to extract photorealistic textures, otrophoto and realistic databases based on the point cloud, and therefore on the overlapping of hundreds or thousands of frames. From a geometrical point of view, we are therefore able to process any type of information and to study and analyse it succinctly without resorting to subsequent inspections or further relevant campaigns.

There are four obvious advantages of 3D laser scanner relief technique or photogrammetric image-based technique compared to traditional survey techniques:

- High-detail restitution in situations of particular complexity;

- Reduction of relief and restitution times;

- Acquisition of simultaneously 3D point clouds and colour photos;

- Integration with 3D CAD and BIM modelling systems.

This model is as detailed as it is effective and allows the modeller to complete the cognitive framework that a heritage building restoration intervention requires; that is, a pathological diagnostic study [9].

However, it is advisable today to recognize that the BIM methodology, despite being in a growing phase, should be integrated with traditional methods and information, based on CAD and traditional survey. The collation and reworking of all the information obtained through different platforms such as Revit, Photoscan, Recap, allows the integration between the "point cloud" generated by the photogrammetric model and the traditional information such as measurements, photos and pathological relief within a single parametric model from which it is possible to extract the individual components in the form of excel tables or object libraries. According to Grabowski's words, "BIM software is becoming commonplace, yet design software that uses $2 \mathrm{D}$ linework will remain popular for the foreseeable future. These two different approaches to design mean that a hybrid workflow becomes part of everyday practice. For design firms to remain competitive, it is worthwhile for them to establish a solid hybrid workflow - for themselves, their partners, and their clients" [5].

In a context like the Medina of Tetuán, characterized by very small, labyrinthine streets, and by lighting coming only from the internal patio, we were able to verify that it still necessary to implement the hybrid workflow in some areas and contexts. Even more so it is indispensable due to the presence of a strong traditional connotation in architecture and engineering, especially in the restorative field, often characterized by techniques handed down from generation to generation.

The subsequent parameterization of this information through the BIM model allows a considerable improvement in the management of the facilities and therefore of the life cycle of the case study. In fact, the goal of H-BIM is not just the mere graphic representation of the case study "as it is", but also being able to study any characteristic pathology of the "as damaged" building from a $360^{\circ}$ point of view, so as to be able to propose restorative solutions and to be able to carry out a well-managed asset.

\section{THE CASE STUDY}

The objective was to demonstrate that a project can be carried out by implementing the BIM methodology in the restorative field with minimum possible resources. 
Although the ultimate aim is to create a virtual BIM prototype through a hybrid database that can contain both traditional information together with economic and social information, in this project it was necessary to base everything on a photogrammetric survey carried out in the shortest possible time and with only one reflex camera and a tripod. Nowadays the implementation of virtual reality, the realization of scans through laser scanners and the development of companies that deal only with augmented reality make us pose a question: Is H-BIM accessible to everyone? Are there resources to produce parameterizable information that are truly economical and easy to use?

The photogrammetric investigation process highlighted the difficulties that a site like the Medina of Tetuán and the use of a simple reflex camera within a building typology such as the Moroccan patio house can present. Despite these challenges, it was possible to create partial or total photogrammetric models of different patio houses, making the choice fall on the architecture that presented a more complex pathological picture.

Using SfM (Structure from Motion) algorithms, completed by stereo matching algorithms, the post-production of the base frames becomes of fundamental importance for the success of a terrestrial photogrammetric model. To do this, shots that allow overlapping of $60-70 \%$ of the surface must be taken to cover the entire surface under examination, but at the same time obtain a large number of overlapping points and comparable geometries for data processing [6].

The possibility of not completely automating the photogrammetric modelling process but being able to enter the camera mechanism allows a much more pragmatic and experimental approach to technological innovation; setting such as focal distances, overlapping, white balance and subsequent settings during image processing can be adjusted. The architect is thus trying to merge his traditional and photographic-perspective skills with new technological evolutions such as Agisoft Photoscan (Fig. 1) or Autodesk Recap platforms. A sort of journey into the past, material and physical, studied through a look to the future.

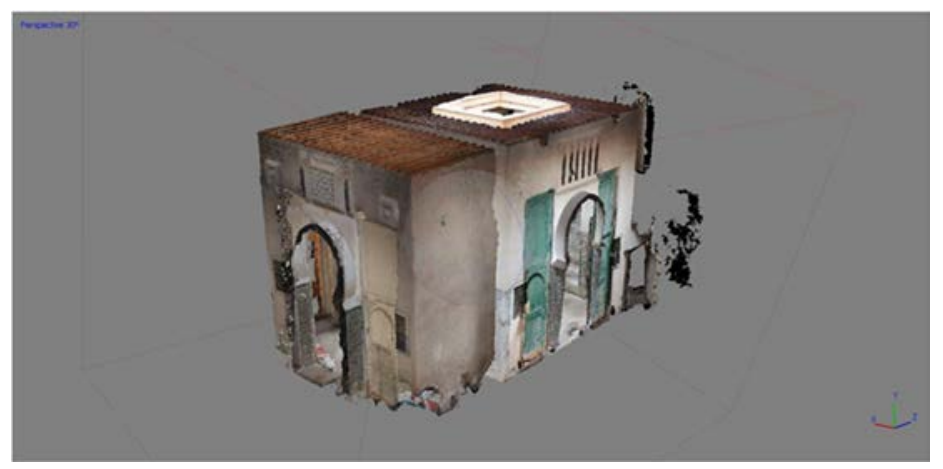

Figure 1: Tetuán, Morocco, case study, photogrammetry. Software: Photoscan.

Being able to integrate different platforms with the same purpose allows us to create a set of shared design parameters or simply information that can recognize and be associated with different facades and different pathologies present in the case study, exporting and/or importing the photogrammetric model in relation to the use required. In our case, we chose to focus our study on the relationship that an H-BIM survey can have with a parametric model in order to create a specific methodology on the study and diagnostic framework of building diseases. 
The basis of this study requires a cataloguing of the possible pathologies present in the building heritage so that a methodological guideline can be easily applied to other case studies and architectures. In fact, in the near or remote future, the possibility of being able to make a catalogue of the viviendas of the Medina of Tetuán is very stimulating both from a historical point of view, allowing us to store a realistic and three-dimensional photo of a historical centre for UNESCO, but also from an engineering point of view. Before modelling, a guideline was created both in regards to the state of degradation and in regards to the diagnosis of pathologies in theoretical terms, subsequently used as a basis for the creation of design parameters and shared parameters in Revit.

All possible pathologies have been decoded using the guidelines for the recognition of the main degradation phenomena realized by Stefano Francesco Musso in "Recupero e restauro degli edifici storici: guida pratica al rilievo e alla diagnostica." More pathologies were added to this list in addition to the ones present on this particular building, so that this database that can be used on other case studies present in the Medina of Tetuán. The subsequent mapping of the decay was therefore carried out with greater ease and through three different methodologies, all aimed at the parameterization of the individual pathologies.

The first methodology allowed to create an object through the editor of the Revit families. Once the mesh model was cleaned in Photoscan, thus identifying the individual areas presenting a specific pathology, the model was exported in .obj format for subsequent importation into Rhynoceros. Once the model in Rhynoceros was imported, the reduction of the surfaces of the mesh began, and the subsequent transformation into Nurbs through the command MeshANurbs. The surface thus created was exported from Rhynoceros in Dxf format (Autocad drawing exchange) and imported into Revit within the family editor, assigning it the pathological shared parameter previously created [4].

The second methodology consists of creating 2D annotative boxes directly in the project files, using the point cloud, mapping the areas with the different degradations both in plan and in section, and giving each one a different recognizing pattern.

The third methodology consists in assigning the different shared parameters to the individual elements modelled in relation to their pathologies, so as to obtain a personalized information database in the very properties of the element (wall, column, window).

The subsequent parametric modelling can be seen in Fig. 2.

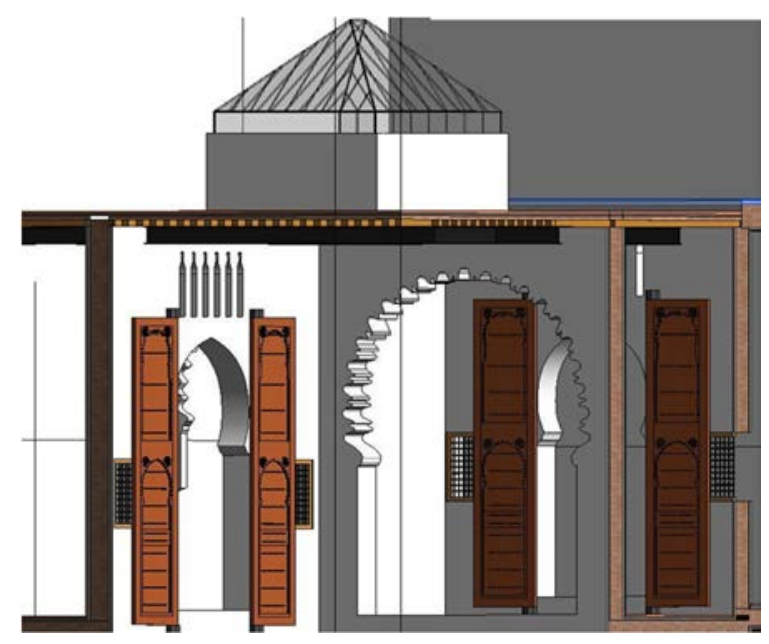

Figure 2: Tetuán, Morocco, case study: Axonometry, parametric model. Software: Revit. 
However, it has been greatly facilitated by the photogrammetric survey for several reasons:

- the possibility of extrapolating photographic, volumetric and pattern information that allows us a subsequent realistic consultation of the case study;

- the possibility of obtaining different and often more accurate measurements compared to traditional measures;

- a pathological diagnostic analysis is no longer only in the form of surface relief pathologies of the various facades or an information catalogue. Besides, information integrated into the single object modelled in the virtual prototype can be utilised in the use of BIM, thus helping form a unique digital process [9].

The comparability of these descriptive parameters realised on the basis of pathological diagnostic manuals and the continuous parametric updatability within the model allows for a $360^{\circ}$ study of the building heritage.

The possibility of being able to manage different design phases combined with the different historical periods as well as different project proposals in turn related to the actual status of the building heritage allows us to examine the whole historical process of the building heritage itself. The ultimate goal is to safeguard each of the building heritage's peculiar and significant aspects.

Therefore, by comparing different phases (see Fig. 3) and different eras, the constant updating of the virtual BIM prototype allows us to add or delete information, thus updating the content of the model both from a geometric and an informative point of view. The thin line, therefore, between an "as-built" model, an "as is" model and an "as damaged" model turns out to be of fundamental importance in a restoration project, hence also permitting to study the evolution of the pathologies encountered overtime or the different deterioration phases that the case study has undergone. It's so possible to understand the building with different point of view and different details carrying out a pathological study both graphic (see Fig. 4) and data-driven (see Fig. 5).
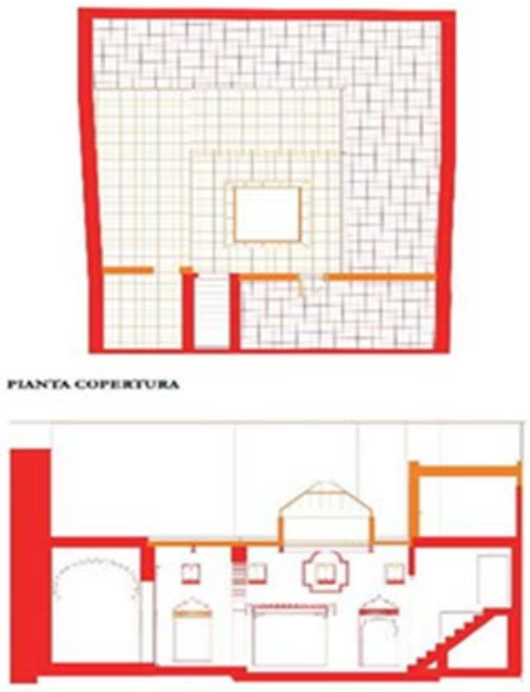

Nacions
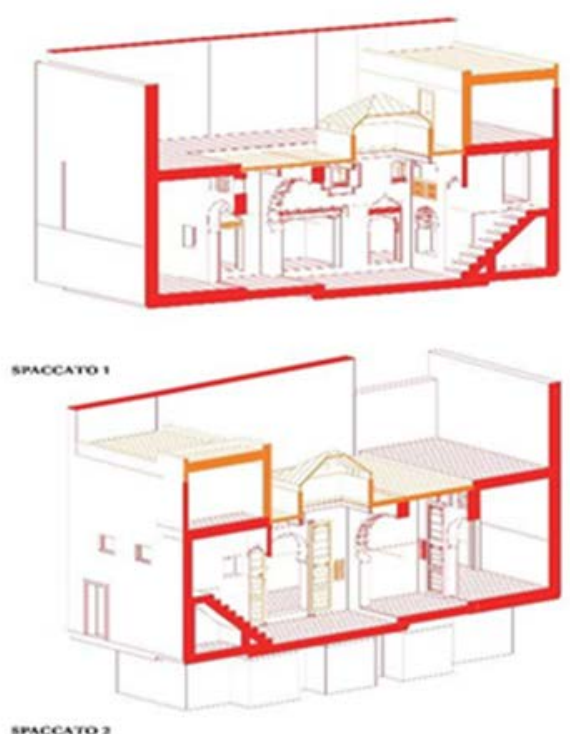

smecaros

Figure 3: Case study: Phase management, parametric model. Software: Revit. 

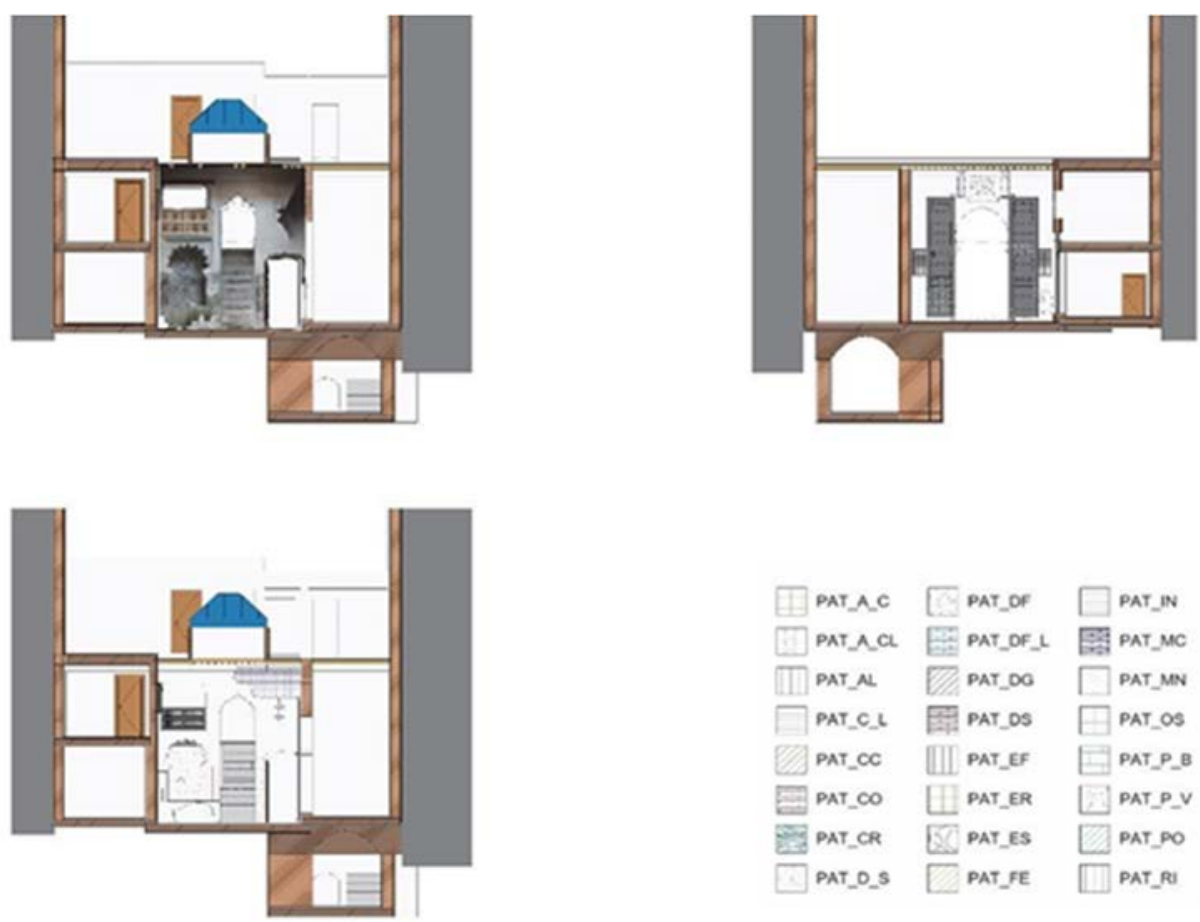

Figure 4: Case study: diagnostic-pathological study, parametric model. Software: Revit.

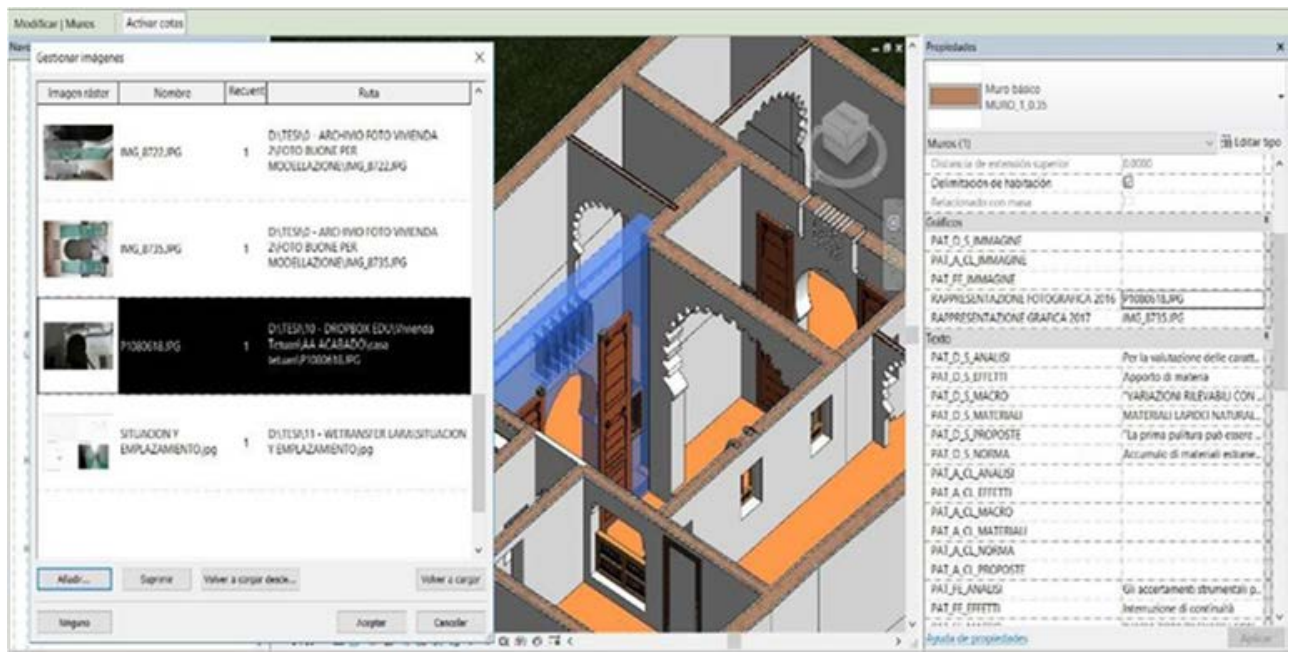

Figure 5: Case study: pathological study, parametric model. Software: Revit.

This extraction of databases is crucial. Because of its complexity, the database must be clear and legible for everyone including less specialized. in the fact that the architect needs to interact with anyone in the case study. 
Interacting with different actors in the building process is in fact essential should a designer be involved in any aspects concerning a building heritage. Interaction is necessary to implement an interoperable process on two main lines: the first concerns the possibility to interchange data between different software and manufacturers through different formats and Industry Foundation Classes (IFC); the second concerns communication between the actors of the building process, which will necessarily have different skills and the ability to use software that is certainly diversified.

In order to simplify communication and interaction and to reduce the gap between different actors in the building process, viewers and applications such as Tekla BIM Sight or Solibri Model can be used.

Moreover, in a final way of visualization and $360^{\circ}$ total experience, should be used and developed a full immersion model as virtual reality (see Fig. 6) or augmented reality to guarantee a wider experience to the client or everyone who wants to know more about the case study.

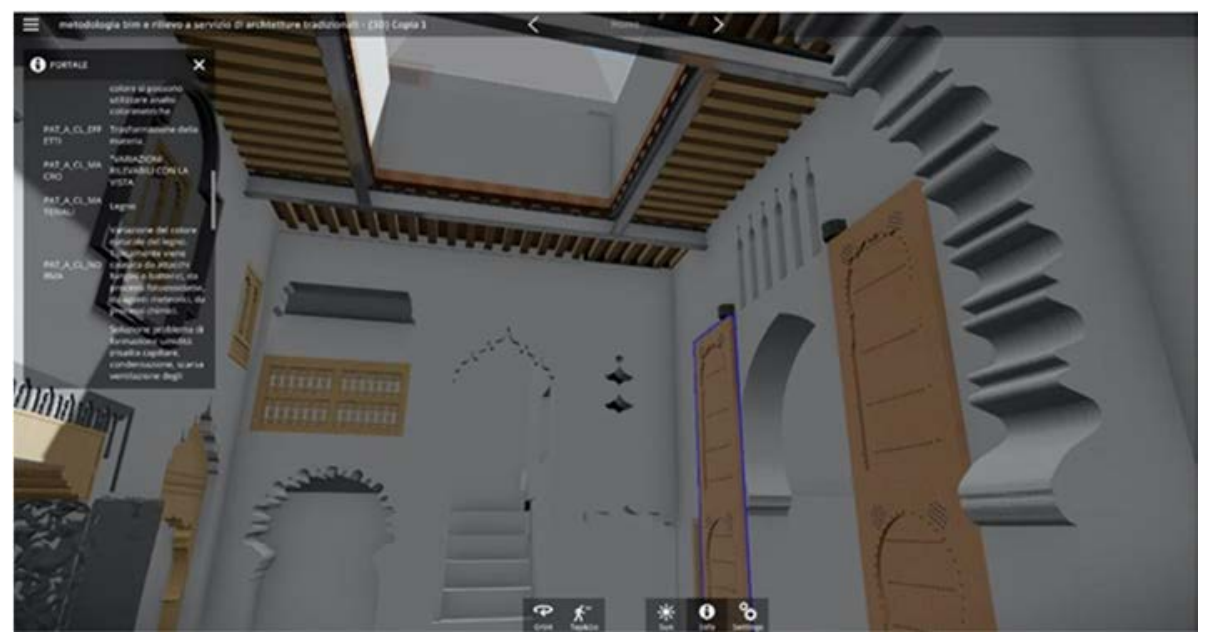

Figure 6: Case study: Virtual reality, parametric model. Software: Revit Live.

The architect must therefore be able to think of how the model and the project itself, with all its information, can be communicative and can stimulate the observer in order to be able to interact at a $360^{\circ}$ scale. The ability of an H-BIM model to select a wall and graphically be able to read and visualize all its features makes the H-BIM model a facilitator within the building process and restoration of traditional architecture. As a result of that, H-BIM methodology allows not only to manage but also to study a complex asset composed of several factors, accordingly managing its life cycle management process and its restoration or conservation. Being able to guarantee a constant updating of the information of the model even before the restoration work is carried out, allows to take into account any aspect related to the model from the traditional construction technique to the quality of the materials used. The simple diagnostic-pathological comparison over time, the possibility of managing different project phases or different construction phases that have developed in the past, or even the extraction of parameterised tables and schedules in common formats such as Excel, guarantee that the H-BIM project is interoperable and integrated in a collaborative capacity, thus favouring easy management of the building. 


\section{CONCLUSION}

In a contest like Morocco, Tetuán in particular, it is even more necessary and obvious that BIM must be understood and made available to users and professionals who do not have access to this methodology and knowledge. The goal of expanding the methodology into social and professional groups extraneous to this information is an important integrative social and architectural component of the Medina of Tetuán itself.

Even more so when, at the base of the research, there is a much larger and more ambitious project than the simple restoration of a house or a building complex.

Citing Professor Benaboud, promoter and one of the leading investigator of the Moroccan research group "The idea is to create a circuit: a house of the 18th century (with a bamboo roof), a house of the 18/19th century (wood), and a house of the 19/20th century with iron components. So there are three houses of different centuries and you can see how the construction has evolved; the different materials, the different construction techniques". And furthermore, "I wonder what use we can have for these homes in the Medina. For me the first thing is to restore them well and make an awareness campaign. Then a historical circuit would become possible to rent them through a management company. The objective is to inspire other people to intervene" [7]. Therefore, the goal of the path undertaken by the University of Alicante years ago is to create a catalogue of viviendas within the Tetuán medina realized with BIM methodology. The whole complex of the medina could benefit greatly from other surveys in addition to the photogrammetric one that was carried out for this study; laser scanners and drones would aid in preserving a parametric restorative database which would benefit the whole etuanie community thus initiating a virtuous path aimed of recovering this UNESCO heritage that is beginning to present structural failures.

The extreme consequence of this methodology is to have to ensure that in the future other readings can be taken, based on knowledge resources and cognitive skills different from ours, and - more importantly - all equally legitimate. The project that must follow from this attitude should be respectful of the pre-existing traces and aware that the measure of contemporary intervention should be limited to superimposing new levels of writing on existing ones, in a text that remains open to multiple reading abilities. In fact, the work must be "recognized as a text, defending its intrinsic hermeneutical value" with the intention of assigning to the conservation the ambitious goal of "protecting the opportunity to understand" [8], thus legitimizing the following new interpretations. In addition, the direct analysis of an artefact, adequately supported by the execution of instrumental analysis if necessary, allows us to recognize the problems related to the degradation of the materials along with the changing geometric and spatial configurations, with the potential instability of the structures and, ultimately, with the mechanisms of injury, orientating the conservation project in a timely manner.

\section{ACKNOWLEDGEMENTS}

The authors want to acknowledge Professor Benaboud's kind inclination and all members of Tetuán's research team to make the case study possible.

\section{REFERENCES}

[1] Braudel, F., La Méditerranée et le Monde méditerranéen à l'époque de Philippe II, Colin: Paris, passim, 1949.

[2] Francovich, R. \& Bianchi, G., L'archeologia dell'elevato come archeologia. Arqueologia de la Arquitectura, 1, pp. 101-111, 2002. 
168 Building Information Modelling (BIM) in Design, Construction and Operations III

[3] Mileto, C. \& Vegas-Lopez Manzanares, F., El Análisis estratigráfico constructivo como estudio previo al proyecto de restauración arquitectónica: metodología y aplicación. Arqueología de la Arquitectura, 2, pp. 189-196, 2003.

[4] Lopez, F., Lerones, P.M., Llamas, J., Gómez-García-Bermejo, J. \& Zalama, E., A review of heritage Building Information Modeling (H-BIM). Multimodal Technologies and Interaction, 2(21), 2018.

[5] Grabowski, R., CAD \& BIM - Is there a free pass?, Graphisoft, p. 32, 2010.

[6] Monti, C. \& Selvini, A., Topografia, fotogrammetria e rappresentazione all'inizio del ventunesimo secolo: strumenti e modalità operative, Maggioli: Santarcangelo di Romagna, 2015.

[7] Benaboud, Conversations in Tetuán with Profesor Benaboud during different travels.

[8] Torsello, B.P., Conservare e comprendere. Il Progetto del Passato: Memoria, Conservazione, Restauro, Architettura, ed. B. Pedretti, Bruno Mondadori: Milano, pp. 179-200, 1997.

[9] Delgado-Jimenez, A. \& Lloret, J., Health, Wellbeing and Sustainability in the Mediterranean City, Routledge: London, 2019. 